\title{
Características agronômicas e bromatológicas do milho submetido a adubações com potássio na produção de silagem ${ }^{1}$
}

\author{
Agronomic and bromatologic characteristics of maize subjected to potassium \\ fertilization in silage production
}

\author{
Flávio Henrique Silveira Rabêlo ${ }^{2 *}$, Adauton Vilela de Rezende ${ }^{3}$, Carlos Henrique Silveira Rabelo e Fernando $^{4}$ \\ Almeida Amorim5
}

\begin{abstract}
RESUMO - Objetivou-se avaliar doses e formas de aplicação do potássio nas características agronômicas e bromatológicas na cultura do milho para ensilagem. O experimento foi conduzido na UNIFENAS durante o ano agrícola de 2008/2009. A adubação de plantio e a semeadura foram realizadas manualmente, utilizando-se $120 \mathrm{~kg} \mathrm{ha}^{-1} \mathrm{de}_{2} \mathrm{O}_{5}, 30 \mathrm{~kg} \mathrm{ha}^{-1}$ de $\mathrm{N}$, o potássio foi aplicado de acordo com os tratamentos. $\mathrm{O}$ delineamento experimental utilizado foi em blocos casualizados, em arranjo fatorial 4x2, com quatro repetições, fazendo-se uso de quatro doses $\left(0 ; 60 ; 90\right.$ e $\left.120 \mathrm{~kg} \mathrm{ha}^{-1}\right)$ e duas formas de aplicação do $\mathrm{K}$ ( $100 \%$ no plantio e $50 \%$ no plantio $+50 \%$ em cobertura). A interação entre os fatores doses e forma de aplicação do potássio não foi significativa $(\mathrm{p}>0,05)$ para as variáveis estudadas, passando-se a estudar o efeito principal de cada fator. Não houve efeito $(p>0,05)$ das doses de K sobre as porcentagens de MS e plantas acamadas, produtividade de MS e grãos e participação de grãos na massa. A maior produtividade de grãos foi obtida empregando-se o $\mathrm{K}$ totalmente no plantio $(\mathrm{p}<0,05)$. Elevadas doses de potássio não proporcionaram mudanças para MS, porcentagem de plantas acamadas, produtividade de MS, produtividade de grãos e porcentagem de grãos na planta. As diferentes doses e formas de aplicação de potássio não alteram as características bromatológicas da silagem de milho.
\end{abstract}

Palavras-chave: Conservação de volumoso. Matéria seca. Produtividade. Zea mays.

\begin{abstract}
The aim was to evaluate levels and forms of application of potassium on the agronomic and alimentary characteristics of corn used for silage. The experiment was carried out at UNIFENAS during the agricultural year of 2008/2009. Fertilization at planting and sowing was performed manually using $120 \mathrm{~kg} \mathrm{ha}^{-1} \mathrm{P}_{2} \mathrm{O}_{5}$ and $30 \mathrm{~kg} \mathrm{ha}^{-1} \mathrm{~N}$, the potassium being applied according to the treatments. The experimental design used was of randomized blocks in a $4 \times 2$ factorial arrangement with four replications, using four amounts $\left(0 ; 60 ; 90\right.$ and $\left.120 \mathrm{~kg} \mathrm{ha}^{-1}\right)$ and two forms of application of $\mathrm{K}(100 \%$ at planting and $50 \%$ at sowing $+50 \%$ coverage). The interaction between the factors of amount and forms of application of the potassium was not significant $(p>0.05)$ for the variables studied: the main effect of each factor was then investigated. There was no effect ( $p>0.05$ ) for K levels on the percentage of dry matter (DM) and bedded plants, DM and grain productivity and grain participation in the mass. The highest grain yield was obtained when using $\mathrm{K}$ at planting $(\mathrm{p}<0.05)$. High doses of potassium did not produce changes in DM, percentage of bedded plants, DM production, grain yield or grain percentage of the plant. The different levels and forms of application of potassium do not alter the alimentary characteristics of corn silage.
\end{abstract}

Key words: Conservation of bulk. Dry matter. Productivity. Zea mays.

\footnotetext{
*Autor para correspondência

${ }^{1}$ Recebido para publicação em 29/01/2012; aprovado em 03/12/2012

Parte da Dissertação de Mestrado do quarto autor

${ }^{2}$ Departamento de Ciência do Solo, Programa de Pós-Graduação em Solos e Nutrição de Plantas, Escola Superior de Agricultura "Luiz de Queiroz”/ ESALQ, Piracicaba-SP, Brasil, flaviohsr.agro@yahoo.com.br

${ }^{3}$ Instituto de Ciências Agrárias, Universidade José do Rosário Vellano/UNIFENAS, Alfenas-MG, Brasil, adauton.rezende@unifenas.br

${ }^{4}$ Departamento de Zootecnia/Programa de Pós-Graduação em Zootecnia/Universidade Estadual Paulista "Júlio de Mesquita Filho"/UNESP, Jaboticabal-SP, Brasil, carlos.zoo@ hotmail.com

${ }^{5}$ Instituto de Ciências Agrárias/UNIFENAS, Programa de Pós-Graduação em Ciência Animal, Alfenas-MG, Brasil, fernandoamorim@ zootecnista.com.br
} 


\section{INTRODUÇÃO}

O elevado valor energético, grande produção de massa por área (POSSENTI et al., 2005), baixo teor de fibra, colheita mecanizada facilitada e bom padrão de fermentação da silagem fazem do milho uma das forragens mais utilizadas na nutrição de ruminantes (PEREIRA et al., 2004), pois, resulta em melhor desempenho animal comparado a outras fontes de volumosos (MACITELLI et al., 2007). Segundo Zopollatto et al. (2009), a produtividade do milho para silagem está relacionada a características inerentes à planta, como ciclo, altura da planta e proporção de grãos, e ao ambiente, como condições climáticas, densidade de semeadura, época de corte e tratos culturais.

No Brasil, o milho é cultivado nas mais variadas condições edafoclimáticas, onde, o potássio $(\mathrm{K})$ é fornecido via adubação, sendo calculado com base na análise química do solo e com auxílio de tabelas de recomendações nas quais são desconsideradas as interações que ocorre entre os elementos no solo, sendo que a disponibilidade de $\mathrm{K}$ varia conforme o tipo de solo, nível inicial no solo, saturação de $\mathrm{Ca}$ e $\mathrm{Mg}$ na solução do solo e material genético da planta (ANDREOTTI et al., 2001).

$\mathrm{O} \mathrm{K}$ do solo é formado pelo $\mathrm{K}$ da solução, $\mathrm{K}$ trocável e não trocável e o $\mathrm{K}$ estrutural. E o suprimento deste nutriente para as plantas advém da solução e dos sítios de troca dos colóides do solo, que estão em equilíbrio com o $\mathrm{K}$ não trocável e estrutural dos minerais (OTTO; VITTI; LUZ, 2010). O teor trocável é a principal fonte de reposição do K para a solução, o qual pode ser absorvido pelas plantas, adsorvido às cargas negativas do solo ou perdido por lixiviação (FARIA et al., 2012). Portanto, recomenda-se realizar a aplicação desse nutriente conforme as plantas se desenvolvam, visando reduzir perdas no sistema e aumentar a sua eficiência de utilização (OTTO; VITTI; LUZ, 2010). Contudo, Karlen et al. (1988) ressaltam que as plantas de milho têm uma demanda inicial de $\mathrm{K}$ elevada, acumulando cerca de $40 \%$ de todo o $\mathrm{K}$ necessário para seu desenvolvimento em apenas 52 dias após a emergência.

Na planta de milho o $\mathrm{K}$ apresenta alta mobilidade entre células individuais, tecidos e no transporte a longa distância via xilema e floema. É o cátion mais abundante no citoplasma, também ocorrendo em alta concentração no cloroplasto, sendo necessário para neutralizar ânions orgânicos e inorgânicos e para estabilizar o pH da planta entre 7 e 8, faixa ótima para a maioria das reações enzimáticas (MALAVOLTA et al., 1997).

O efeito do K nas características bromatológicas de forrageiras é menos pronunciado, contudo, a deficiência desse nutriente reduz o acúmulo de carboidratos. O K pode aumentar o teor de proteína da planta por participar da ativação de enzimas, fotossíntese, translocação de assimilados e absorção de nitrogênio (MARSCHNER, 1995). Perry et al. (1972) observaram aumento na produção de MS no milho ao aplicarem $339 \mathrm{~kg} \mathrm{ha}^{-1}$ de K, entretanto, a composição bromatológica das silagens e a digestibilidade da MS obtidas ( 0 e $339 \mathrm{~kg} \mathrm{ha}^{-1}$ de $\mathrm{K}$ ) foram semelhantes.

Visando aumentar a produtividade agrícola e melhorar os produtos gerados é importante demonstrar as necessidades nutricionais das diversas culturas e suas respostas aos níveis e formas de adubação (GONÇALVES JUNIOR et al., 2007). Portanto, objetivou-se avaliar doses e formas de aplicação do potássio nas características agronômicas e bromatológicas na cultura do milho para ensilagem.

\section{MATERIAL E MÉTODOS}

$\mathrm{O}$ experimento foi conduzido no Instituto de Ciências Agrárias da Universidade José do Rosário Vellano - UNIFENAS, Alfenas - MG, durante o ano agrícola de 2008/2009, em solo classificado como Latossolo Vermelho escuro (LE). A fertilidade do solo foi determinada em amostras retiradas nas profundidades de $0-20 \mathrm{~cm}$ e $20-40 \mathrm{~cm}$ (Tabela 1 ).

De acordo com a Comissão de Fertilidade do Solo do Estado de Minas Gerais (RIBEIRO; GUIMARÃES; VENEGAS, 1999), os valores de $\mathrm{pH}, \mathrm{P}, \mathrm{K}^{+}, \mathrm{Ca}^{2+}, \mathrm{Mg}^{2+}$, acidez trocável $\left(\mathrm{Al}^{3+}\right)$, acidez potencial $(\mathrm{H}+\mathrm{Al})$, soma de bases (SB), CTC efetiva (t), CTC potencial (T), saturação por bases $(\mathrm{V})$, saturação por alumínio $(\mathrm{m})$ e matéria orgânica (M.O.) foram considerados baixo, muito baixo, médio (camada de 0-20) e baixo (camada de 20-40), médio, médio, baixo, médio, médio, médio, médio, baixo, muito baixo e médio, respectivamente.

O local onde se realizou o plantio do milho possui altitude média de $880 \mathrm{~m}$, e as condições climáticas durante o período vegetativo do milho podem ser verificadas na Figura 1.

A correção da acidez do solo foi realizada pelo método de saturação por bases, 60 dias antes do plantio, com aplicação manual a lanço de calcário dolomítico com PRNT de $80 \%$ visando elevar a saturação por bases a $70 \%$. A adubação de plantio e a semeadura (dez sementes por metro linear do híbrido Geneze 2004 ${ }^{\circledR}$ ) foram realizadas manualmente. A adubação foi realizada a $10 \mathrm{~cm}$ de profundidade e a semeadura a $5 \mathrm{~cm}$, após prévia incorporação do adubo. Utilizou-se $120 \mathrm{~kg} \mathrm{ha}^{-1}$ de $\mathrm{P}_{2} \mathrm{O}_{5}$ na forma de superfosfato simples e $30 \mathrm{~kg} \mathrm{ha}^{-1}$ de N na forma de uréia, conforme recomendação da Comissão de Fertilidade do Solo do Estado de Minas Gerais 
Tabela 1 - Análise química do solo utilizado no experimento

\begin{tabular}{|c|c|c|c|c|c|c|c|}
\hline Camada & $\mathrm{pH}$ & P - Mehlich & $\mathrm{K}^{+}$ & $\mathrm{Ca}^{2+}$ & $\mathrm{Mg}^{2+}$ & $\mathrm{Al}^{3+}$ & $\mathrm{H}+\mathrm{Al}$ \\
\hline$(\mathrm{cm})$ & $\left(\mathrm{H}_{2} \mathrm{O}\right)$ & \multicolumn{2}{|c|}{-----------mg dm ${ }^{-3}----------$} & \multicolumn{4}{|c|}{ 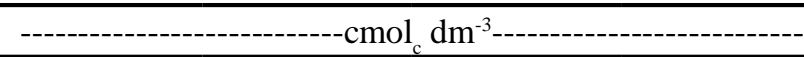 } \\
\hline $0-20$ & 5,4 & 3,0 & 44 & 1,7 & 0,8 & 0,4 & 4,5 \\
\hline $20-40$ & 5,4 & 2,0 & 32 & 1,5 & 0,6 & 0,4 & 4,5 \\
\hline Camada & SB & $\mathrm{t}$ & $\overline{\mathrm{T}}$ & $\mathrm{V}$ & $\mathrm{M}$ & M.O. & P-rem \\
\hline$(\mathrm{cm})$ & \multicolumn{3}{|c|}{ 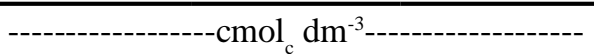 } & \multicolumn{2}{|c|}{----------------\%"---------------- } & dag $\mathrm{kg}^{-1}$ & $\mathrm{mg} \mathrm{L}^{-1}$ \\
\hline $0-20$ & 2,6 & 3,0 & 7,1 & 37 & 13 & 3,1 & 14 \\
\hline $20-40$ & 2,2 & 2,6 & 6,7 & 33 & 15 & 2,8 & 14 \\
\hline
\end{tabular}

(H+Al) - acidez potencial; SB - soma de bases; t - CTC efetiva; T - CTC potencial; V - saturação por bases; $m$ - saturação por alumínio; M.O. - matéria orgânica; P-rem - fósforo remanescente

Figura 1 - Precipitação pluviométrica total, temperatura média, umidade relativa do ar média e fotoperíodo acumulado durante o período vegetativo do milho (novembro de 2008 a fevereiro de 2009)

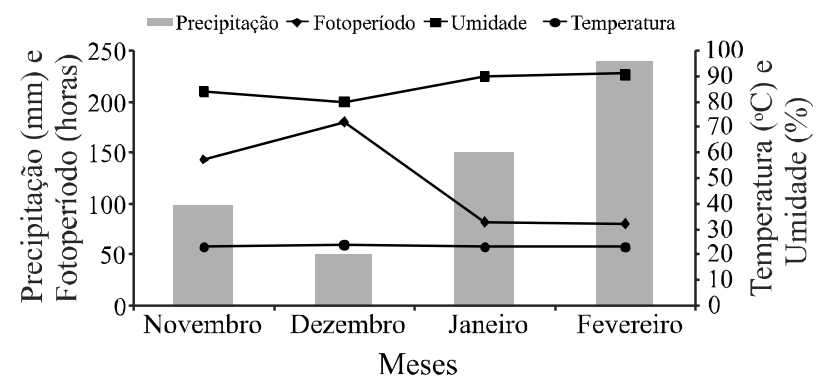

(RIBEIRO; GUIMARÃES; VENEGAS, 1999). O K foi aplicado nas doses de 0; 60; 90 e $120 \mathrm{~kg} \mathrm{ha}^{-1} \mathrm{sob}$ duas formas, $100 \%$ no plantio e $50 \%$ no plantio $+50 \%$ em cobertura na forma de cloreto de potássio $(\mathrm{KCl})$.

Quando as plantas atingiram $20 \mathrm{~cm}$ foi realizado um desbaste obtendo-se estande de 62.500 plantas ha-1. $^{-1}$. Decorridos 30 dias do plantio (quatro pares de folhas completas) realizou-se manualmente uma adubação de cobertura no milho entre as linhas de plantio aplicando-se $160 \mathrm{~kg} \mathrm{ha}^{-1}$ de uréia. O K foi aplicado de acordo com os tratamentos. Realizou-se também o controle de plantas daninhas e da lagarta-do-cartucho (Spodoptera frugiperda) utilizando-se $2,5 \mathrm{~kg} \mathrm{ha}^{-1}$ do pós-emergente Atrazine $^{\circledR}$ (cinco dias após o plantio) e $150 \mathrm{ml} \mathrm{ha}^{-1}$ do inseticida Fastak $100^{\circledR}$, quando as lagartas começaram a atacar as plantas de milho.

O delineamento experimental utilizado foi em blocos casualizados (DBC), com quatro repetições, fazendo-se uso de quatro doses (0; 60; 90 e $\left.120 \mathrm{~kg} \mathrm{ha}^{-1}\right)$ e duas formas de aplicação do K (100\% no plantio e $50 \%$ no plantio $+50 \%$ em cobertura), constituindo um arranjo fatorial $4 \times 2$. As unidades foram compostas por quatro linhas espaçadas a $0,8 \mathrm{~m}$ com $5 \mathrm{~m}$ de comprimento, sendo separadas uma da outra por uma linha de plantio entre um bloco e outro, e por $0,5 \mathrm{~m}$ entre uma parcela e outra, perfazendo uma área de $16 \mathrm{~m}^{2}$ por unidade experimental.

Semanalmente, retiraram-se cinco espigas na área, de forma aleatória, para acompanhamento da redução da linha de leite do grão. Observado o ponto de colheita (entre $1 / 2$ e $2 / 3$ da linha de leite), dez plantas de cada unidade, tomadas aleatoriamente, foram avaliadas em relação à altura, produtividade de MS, produtividade de grãos, participação de grãos na planta e porcentagem de plantas acamadas. Na determinação da altura considerou-se a distância entre o nível do solo e o ponto de inserção da folha bandeira. A produtividade de MS foi determinada multiplicando-se a porcentagem de MS obtida pela produtividade de matéria verde verificada. Ainda optou-se por descontar o peso das plantas acamadas, e posteriormente o peso médio obtido foi convertido em $\mathrm{kg} \mathrm{ha}^{-1}$. A produtividade de grãos foi obtida mediante pesagem dos grãos de dez espigas, com umidade corrigida para $13 \%$, extrapolando-se os resultados para um hectare. A participação de grãos foi calculada com base no peso seco dos grãos em relação ao peso seco da planta, e a porcentagem de plantas acamadas foi determinada por meio da contagem das plantas que estavam acamadas (ângulo superior a $20^{\circ}$ com a vertical) ou quebradas abaixo da espiga ou da panícula, antes da colheita, sendo os valores transformados em porcentagem.

Após a avaliação das características agronômicas, as plantas restantes de cada unidade experimental foram colhidas manualmente a $10 \mathrm{~cm}$ do solo (pois alturas superiores diminuem a quantidade de MS ensilada, além do que, as silagens obtidas com esta altura de corte apresentam bom valor nutritivo) e picadas em picadeira estacionária, com tamanho médio de partícula de 2 a $3 \mathrm{~cm}$ (partículas com tamanho menor podem aumentar as perdas de MS por 
efluentes em plantas com alto teor de umidade), visando obter massa específica entre 550 e $600 \mathrm{~kg} \mathrm{~m}^{-3}$. Uma amostra foi retirada para determinação da MS da planta de milho e parte do material foi ensilada em silos de PVC $\left(10 \mathrm{~cm}\right.$ de diâmetro, $50 \mathrm{~cm}$ de altura e volume $\left.0,0039 \mathrm{~m}^{3}\right)$. No fundo de cada silo, colocou-se $0,5 \mathrm{~kg}$ de areia separada da silagem por duas telas de sombreamento artificial (50\%), que funcionaram como dreno para efluente, e após o enchimento os silos foram fechados com tampas dotadas de válvula tipo Bünsen e lacrados com fita adesiva.

Decorridos 30 dias da ensilagem, os silos foram abertos e o conteúdo superior $(10 \mathrm{~cm})$ de cada silo foi descartado para evitar a contaminação das amostras, salientando ainda que a análise do material deteriorado é interessante do ponto de vista microbiológico (produção de toxinas), visto que os animais não consomem silagem deteriorada, conforme reportado por Jobim et al. (2007). O material central do silo foi homogeneizado e amostrado para determinação da MS da silagem, após sofrer pré-secagem por 72 horas em estufa de ventilação forçada a $55^{\circ} \mathrm{C}$. Estas amostras foram trituradas em moinho do tipo Willye com peneira de crivos de $1 \mathrm{~mm}$ e utilizadas para avaliação das características bromatológicas da silagem.

Os teores de MS, proteína bruta (PB) e valores de $\mathrm{pH}$ da planta de milho e da silagem foram determinados utilizando a metodologia descrita por Silva e Queiroz (2002). A concentração de PB foi obtida pelo produto da multiplicação do teor de $\mathrm{N}$ total e o fator de conversão 6,25. A fibra em detergente neutro (FDN) e fibra em detergente ácido (FDA) foram calculadas segundo metodologia proposta porVan Soest etal.(1991), enquanto a hemicelulose foi determinada por meio da diferença entre os valores de FDN e FDA. A digestibilidade in vitro da matéria seca (DIVMS) foi determinada de acordo com o método das duas etapas proposto por Tilley e Terry (1963). Os valores de nutrientes digestíveis totais (NDT) foram calculados por meio da equação 1 descrita por Rodrigues (2009), assim como os valores de energia digestível (ED) e energia metabolizável (EM) foram obtidos utilizando-se as respectivas equações 2 e 3 .

$$
\begin{aligned}
& \% \mathrm{NDT}=87,84-(0,7 \times \% \text { FDA }) \\
& \mathrm{ED}\left(\mathrm{Mcal} \mathrm{kg}^{-1} \text { de MS }\right)=\% \text { NDT } \times 0,04409 \\
& \text { EM }(\text { Mcal kg-1 de MS })=\text { ED x } 0,82
\end{aligned}
$$

Os dados obtidos foram submetidos à análise de variância utilizando-se o programa estatístico SISVAR ${ }^{\circledR}$ (FERREIRA, 2008), realizando-se estudo de regressão para as doses e comparação de médias pelo teste $\mathrm{F}$ a $5 \%$ de significância para as formas de aplicação do K.

\section{RESULTADOS E DISCUSSÃO}

A interação entre os fatores de estudo (doses e forma de aplicação do potássio) não foi significativa ( $p>0,05)$ nas variáveis estudadas, passando-se a estudar o efeito principal de cada fator, como pode ser observado na Tabela 2 .

Estes resultados permitem inferir que a adubação potássica não altera a porcentagem de MS, embora haja um incremento na produtividade de grãos obtida com a disponibilização deste nutriente às plantas no plantio (Tabela 3). Vilela et al. (2008) avaliaram o valor nutritivo de silagens de milho colhidas em diversos estádios de maturação, utilizando $64 \mathrm{~kg} \mathrm{ha}^{-1}$ de $\mathrm{K}$ no plantio e $40 \mathrm{~kg} \mathrm{ha}^{-1}$ de $\mathrm{K}$ em cobertura (divididos em duas aplicações, 30 e 45 dias após emergência - DAE), e encontraram valores de MS para o híbrido Geneze $2004^{\circledR}$, antes da ensilagem de 34,6 e 39,9\% para as plantas colhidas nos estádios $1 / 2$ e 2/3 da linha de leite, respectivamente.

Verificou-se efeito quadrático das doses de potássio sobre a altura das plantas de milho (Figura 2), estimando-se pela equação, uma altura máxima de 2,81 m, obtido com a aplicação de $97,5 \mathrm{~kg} \mathrm{ha}^{-1}$ de $\mathrm{K}_{2} \mathrm{O}$. Contudo, não houve efeito $(p>0,05)$ da forma de aplicação sobre esta variável (Tabela 3). Andreotti et al. (2001) estudaram o desenvolvimento do milho em função da saturação por bases e da adubação potássica e encontraram alturas de 2,48 e 2,71 m, utilizando 0 e $240 \mathrm{mg} \mathrm{kg}^{-1}$ de $\mathrm{K}$, respectivamente. De acordo com Mello et al. (2004), é importante avaliar a altura das plantas de milho para confecção de silagem, uma vez que esta característica encontra-se diretamente correlacionada com a porcentagem de plantas acamadas, podendo reduzir a produtividade de MS quando há acentuado acamamento, visto que estas plantas não são colhidas pelos maquinários no momento da ensilagem.

Não houve efeito das doses e formas de aplicação do potássio $(\mathrm{p}>0,05)$ sobre a porcentagem de plantas acamadas (Tabela 3), não corroborando com as respostas verificadas por Mello et al. (2004). Segundo Cruz et al. (2003), o acamamento é um fenômeno complexo, e sua expressão depende de fatores genéticos, inter-relacionados com fatores do clima, solo, práticas culturais adotadas e danos causados por pragas e doenças. Castoldi et al. (2011) avaliaram alguns sistemas de cultivo e o uso de diferentes adubos na produção de silagem e grãos de milho e relataram acamamentos extremamente elevados, ao redor de $54,62 \%$, quando utilizaram $30 \mathrm{~kg} \mathrm{ha}^{-1}$ de $\mathrm{K}_{2} \mathrm{O}$ no plantio. Os autores atribuíram este resultado a um possível desequilíbrio entre as absorções de $\mathrm{K} \mathrm{e} \mathrm{N}$.

A produtividade de MS não foi alterada em função das doses e formas de aplicação do $K$ ( $p>0,05)$, possivelmente pelos teores de $\mathrm{K}$ no solo terem sido 
Tabela 2 - Análise de variância das características agronômicas e bromatológicas avaliadas na planta e silagem de milho submetida a doses e formas de aplicação de K

\begin{tabular}{|c|c|c|c|c|c|c|c|}
\hline \multirow{2}{*}{$\mathrm{FV}$} & \multirow{2}{*}{ GL } & \multicolumn{6}{|c|}{ Quadrados Médios } \\
\hline & & MS & Altura & $\mathrm{PA}$ & PMS & PGR & \% Grãos \\
\hline Bloco & 3 & $2,0885^{\text {ns }}$ & $0,0080^{\text {ns }}$ & $1,6145^{*}$ & $2702082^{\text {ns }}$ & $1055790^{\mathrm{ns}}$ & $9,3006^{\mathrm{n}}$ \\
\hline Dose & 3 & $2,7931^{\text {ns }}$ & $0,0344 *$ & $0,1979^{\mathrm{ns}}$ & $3956907^{\mathrm{ns}}$ & $4149595^{\mathrm{ns}}$ & $40,7305^{\mathrm{ns}}$ \\
\hline Forma & 1 & $0,1800^{\text {ns }}$ & $0,0005^{\mathrm{ns}}$ & $0,0312^{\mathrm{ns}}$ & $5915940^{\mathrm{ns}}$ & $34175778 *$ & $196,6144^{*}$ \\
\hline Dose*Forma & 3 & $0,5665^{\text {ns }}$ & $0,0057^{\mathrm{ns}}$ & $0,3645^{\mathrm{ns}}$ & $1763637^{\mathrm{ns}}$ & $4162902^{\mathrm{ns}}$ & $23,1364^{\mathrm{ns}}$ \\
\hline Resíduo & 21 & 1,0909 & 0,0057 & 0,3526 & 2691460 & 1699296 & 20,7885 \\
\hline $\mathrm{CV}(\%)$ & & 3,63 & 2,78 & 126,69 & 8,76 & 13,64 & 15,5 \\
\hline \multirow{2}{*}{ FV } & \multirow{2}{*}{ GL } & \multicolumn{6}{|c|}{ Quadrados Médios } \\
\hline & & MS sil & $\mathrm{pH}$ & PB & FDN & FDA & HEM \\
\hline Bloco & 3 & $3,2515^{\text {ns }}$ & $0,0342^{\text {ns }}$ & $1,7511^{*}$ & $0,3868^{\mathrm{ns}}$ & $0,4107^{\mathrm{ns}}$ & $0,0013^{\mathrm{ns}}$ \\
\hline Dose & 3 & $4,3617^{\text {ns }}$ & $0,0440^{\mathrm{ns}}$ & $0,2219^{\mathrm{ns}}$ & $0,4585^{\mathrm{ns}}$ & $0,4521^{\mathrm{ns}}$ & $0,0040^{\mathrm{ns}}$ \\
\hline Forma & 1 & $0,2775^{\text {ns }}$ & $0,0036^{\mathrm{ns}}$ & $0,5778^{\mathrm{ns}}$ & $0,0128^{\mathrm{ns}}$ & $0,0011^{\mathrm{ns}}$ & $0,0057^{\mathrm{ns}}$ \\
\hline Dose*Forma & 3 & $0,8839^{\text {ns }}$ & $0,0090^{\mathrm{ns}}$ & $0,9486^{\mathrm{ns}}$ & $0,4839^{\mathrm{ns}}$ & $0,4440^{\mathrm{ns}}$ & $0,0016^{\mathrm{ns}}$ \\
\hline Resíduo & 21 & 1,7038 & 0,0179 & 0,3051 & 0,3981 & 0,4047 & 0,0019 \\
\hline $\mathrm{CV}(\%)$ & & 3,63 & 3,65 & 8,33 & 1,27 & 1,28 & 27,77 \\
\hline \multirow{2}{*}{ FV } & \multirow{2}{*}{ GL } & \multicolumn{6}{|c|}{ Quadrados Médios } \\
\hline & & DIVMS & NDT & ED & EM & & \\
\hline Bloco & 3 & $26,7420^{\text {ns }}$ & $0,2493^{\text {ns }}$ & $0,0004^{\mathrm{ns}}$ & $0,0003^{\text {ns }}$ & & \\
\hline Dose & 3 & $11,1560^{\mathrm{ns}}$ & $0,2766^{\mathrm{ns}}$ & $0,0005^{\mathrm{ns}}$ & $0,0003^{\mathrm{ns}}$ & & \\
\hline Forma & 1 & $20,5600^{\mathrm{ns}}$ & $0,0008^{\mathrm{ns}}$ & $0,0000^{\mathrm{ns}}$ & $0,0000^{\mathrm{ns}}$ & & \\
\hline Dose*Forma & 3 & $21,8247^{\mathrm{ns}}$ & $0,2668^{\mathrm{ns}}$ & $0,0005^{\mathrm{ns}}$ & $0,0003^{\mathrm{ns}}$ & & \\
\hline Resíduo & 21 & 23,1332 & 0,2455 & 0,0004 & 0,0003 & & \\
\hline $\mathrm{CV}(\%)$ & & 10,31 & 1,01 & 1,01 & 1,01 & & \\
\hline
\end{tabular}

FV - fonte de variação; GL - graus de liberdade; PA - plantas acamadas (\%); PMS - produtividade de matéria seca (kg ha $\left.{ }^{-1}\right)$; PGR - produtividade de grãos $\left(\mathrm{kg} \mathrm{ha}^{-1}\right) ; \%$ Grãos - participação de grãos na massa; MS sil - matéria seca da silagem (\%); HEM - hemicelulose; ns Não significativo a 5\% de significância, "Significativo a 5\% pelo teste $\mathrm{F}$

Tabela 3 - Características agronômicas da planta de milho submetida a doses e formas de aplicação do potássio

\begin{tabular}{ccccccc}
\hline Dose de $\mathrm{K}_{2} \mathrm{O}\left(\mathrm{kg} \mathrm{ha}^{-1}\right)^{*}$ & $\mathrm{MS}$ & Altura $(\mathrm{m})$ & $\mathrm{PA}(\%)$ & PMS $\left(\mathrm{kg} \mathrm{ha}^{-1}\right)$ & PGR $\left(\mathrm{kg} \mathrm{ha}^{-1}\right)$ & $\%$ Grãos \\
\hline 0 & $29,23 \mathrm{a}$ & - & $0,25 \mathrm{a}$ & $18311 \mathrm{a}$ & $8897 \mathrm{a}$ & $27,41 \mathrm{a}$ \\
60 & $28,43 \mathrm{a}$ & - & $0,50 \mathrm{a}$ & $18534 \mathrm{a}$ & $10187 \mathrm{a}$ & $32,52 \mathrm{a}$ \\
90 & $29,22 \mathrm{a}$ & - & $0,62 \mathrm{a}$ & $19773 \mathrm{a}$ & $10172 \mathrm{a}$ & $29,54 \mathrm{a}$ \\
120 & $28,05 \mathrm{a}$ & - & $0,50 \mathrm{a}$ & $18303 \mathrm{a}$ & $8969 \mathrm{a}$ & $28,16 \mathrm{a}$ \\
\hline Forma de aplicação* & & & & & \\
\hline $100 \%$ plantio & $28,66 \mathrm{a}$ & $2,72 \mathrm{a}$ & $0,50 \mathrm{a}$ & $19160 \mathrm{a}$ & $10590 \mathrm{a}$ & $31,89 \mathrm{a}$ \\
$50 \%$ plan. + 50\% cob. & $28,81 \mathrm{a}$ & $2,71 \mathrm{a}$ & $0,43 \mathrm{a}$ & $18300 \mathrm{a}$ & $8523 \mathrm{~b}$ & $26,93 \mathrm{~b}$ \\
\hline
\end{tabular}

MS = matéria seca; $\mathrm{PA}=$ porcentagem de plantas acamadas; PMS = produtividade de matéria seca; $\mathrm{PGR}=$ produtividade de grãos; \% Grãos = porcentagem de grãos na planta, "Médias seguidas de mesma letra na coluna não diferem entre si pelo teste F a 5\% de significância 
Figura 2 - Altura média das plantas (m) de milho submetidas a doses de potássio

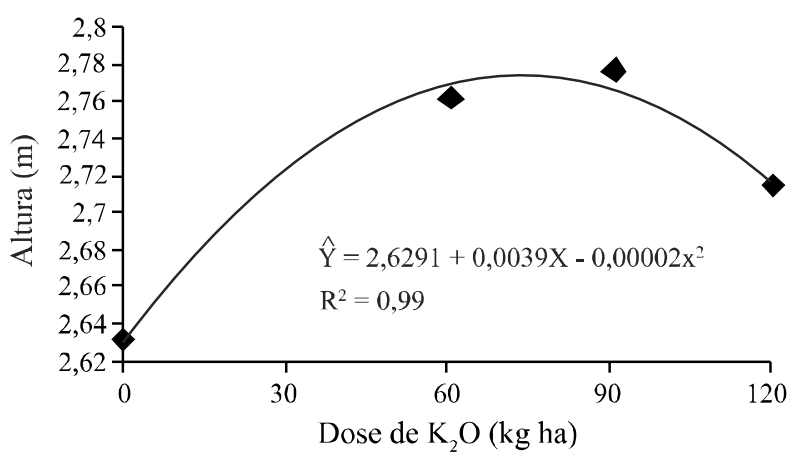

considerados baixo (camada de 0-20 cm) e médio (camada de 20-40 cm). De acordo com Coelho e França (2006), aumentos de produção em função da aplicação de potássio têm sido observados apenas em solos com teores muito baixos desse nutriente. Castoldi et al. (2011) reportaram uma produtividade de MS de $12.503 \mathrm{~kg} \mathrm{ha}^{-1}$ quando utilizaram $30 \mathrm{~kg} \mathrm{ha}^{-1}$ de $\mathrm{K}_{2} \mathrm{O}$ no plantio.

A produtividade de grãos não foi afetada $(\mathrm{p}>0,05)$ pelas doses de potássio (Tabela 3). No entanto, a aplicação de todo o $\mathrm{K}$ no plantio proporcionou maior produtividade de grãos ( $\mathrm{p}<0,05)$, demonstrando a elevada demanda inicial por $\mathrm{K}$, uma vez que as plantas, em geral, acumulam cerca de $40 \%$ de todo o K necessário para seu desenvolvimento em apenas 52 DAE (KARLEN et al., 1988).

As doses de potássio não alteraram a participação de grãos na massa $(p>0,05)$, todavia, houve maior participação de grãos $(\mathrm{p}<0,05)$ quando $100 \%$ do $\mathrm{K}$ foi empregado no plantio, devido a maior produtividade de grãos, como pode ser verificado na Tabela 3 .

Os valores de MS, pH, PB, FDN, FDAe hemicelulose das silagens não foram afetados $(p>0,05)$ pelas doses e formas de aplicação do K (Tabela 4). Os teores de MS das silagens foram superiores aos valores observados na planta de milho, o que pode ser atribuído a elevadas perdas de MS durante o processo fermentativo, haja visto que a perda de efluentes é elevada em silagens com teor de MS inferior a 30\% (SILVA et al., 2011). Resultados semelhantes ao desta pesquisa foram encontrados por Vilela et al. (2008), que reportaram valores de MS de 34,9 e 40,9\%, para silagens confeccionadas a partir de plantas colhidas quando apresentavam $1 / 2$ e 2/3 da linha de leite, respectivamente.

Verificaram-se valores de $\mathrm{pH}$ entre 3,57 e 3,72 nas silagens produzidas (Tabela 4). Van Soest (1994) menciona que em silagens com alto teor de MS (> 35\%), o pH torna-se um parâmetro de pouca importância, pois o desenvolvimento da acidez é inibido pela deficiência de água e pela alta pressão osmótica, de forma que silagens com $\mathrm{pH}$ entre 3,6 e 4,2 podem ser de boa qualidade. Os resultados encontrados nesta pesquisa são semelhantes aos relatados por Vilela et al. (2008), que encontraram valores de $\mathrm{pH}$ 3,52 e 3,61 para silagens confeccionadas a partir de plantas colhidas quando apresentavam 1/2 e 2/3 da linha de leite, respectivamente.

Os valores de PB não foram alterados pelas doses e formas de aplicação do $K(p>0,05)$, apresentando uma amplitude de 0,37 unidades percentuais com a utilização de 60 e $0 \mathrm{~kg} \mathrm{ha}^{-1}$ de $\mathrm{K}_{2} \mathrm{O}$, respectivamente (Tabela 5). De acordo com Marschner (1995) a resposta do teor de proteína às doses de $\mathrm{K}$ deveria ser linear, pelo fato do K possuir papel fundamental na nutrição das plantas, sendo o cátion em maior concentração, um nutriente com relevantes funções fisiológicas e metabólicas, como ativação de enzimas, fotossíntese, translocação de assimilados e também absorção de nitrogênio e síntese protéica, tornando-se importante para a produção e qualidade da forragem.

Considerando-se que teores de PB inferiores a $7 \%$ são limitantes à produção animal, por implicarem em menor consumo voluntário, redução na digestibilidade

Tabela 4 - Composição químico-bromatológica de silagens de milho (\% MS) submetidas a doses e formas de aplicação do potássio

\begin{tabular}{ccccccc}
\hline Dose de $\mathrm{K}_{2} \mathrm{O}\left(\mathrm{kg} \mathrm{ha}^{-1}\right)^{*}$ & MS silagem & $\mathrm{pH}$ & $\mathrm{PB}$ & FDN & FDA & Hemicelulose \\
\hline 0 & $36,54 \mathrm{a}$ & $3,72 \mathrm{a}$ & $6,75 \mathrm{a}$ & $49,71 \mathrm{a}$ & $39,57 \mathrm{a}$ & $10,13 \mathrm{a}$ \\
60 & $35,54 \mathrm{a}$ & $3,62 \mathrm{a}$ & $6,38 \mathrm{a}$ & $50,10 \mathrm{a}$ & $39,91 \mathrm{a}$ & $10,18 \mathrm{a}$ \\
90 & $36,53 \mathrm{a}$ & $3,72 \mathrm{a}$ & $6,68 \mathrm{a}$ & $50,06 \mathrm{a}$ & $39,91 \mathrm{a}$ & $10,14 \mathrm{a}$ \\
120 & $35,06 \mathrm{a}$ & $3,57 \mathrm{a}$ & $6,71 \mathrm{a}$ & $49,63 \mathrm{a}$ & $39,45 \mathrm{a}$ & $10,17 \mathrm{a}$ \\
\hline Forma de aplicação* & & & & & \\
\hline $100 \%$ plantio & $35,82 \mathrm{a}$ & $3,65 \mathrm{a}$ & $6,76 \mathrm{a}$ & $49,89 \mathrm{a}$ & $39,72 \mathrm{a}$ & $10,17 \mathrm{a}$ \\
$50 \%$ plan. + 50\% cob. & $36,01 \mathrm{a}$ & $3,67 \mathrm{a}$ & $6,50 \mathrm{a}$ & $49,85 \mathrm{a}$ & $39,71 \mathrm{a}$ & $10,14 \mathrm{a}$ \\
\hline
\end{tabular}

MS = matéria seca; $\mathrm{pH}=$ potencial hidrogeniônico; $\mathrm{PB}=$ proteína bruta; FDN = fibra em detergente neutro; FDA = fibra em detergente ácido, ${ }^{*}$ Médias seguidas de mesma letra na coluna não diferem entre si pelo teste $\mathrm{F}$ a $5 \%$ de probabilidade 
Tabela 5 - Coeficientes de digestibilidade in vitro da matéria seca e valor energético de silagens de milho submetidas a doses e formas de aplicação do potássio

\begin{tabular}{ccccc}
\hline Dose de $\mathrm{K}_{2} \mathrm{O}\left(\mathrm{kg} \mathrm{ha}^{-1}\right)^{*}$ & DIVMS & NDT & ED & EM \\
\hline 0 & $57,22 \mathrm{a}$ & $49,22 \mathrm{a}$ & $2,1701 \mathrm{a}$ & $1,7795 \mathrm{a}$ \\
60 & $54,95 \mathrm{a}$ & $48,95 \mathrm{a}$ & $2,1583 \mathrm{a}$ & $1,7698 \mathrm{a}$ \\
90 & $56,76 \mathrm{a}$ & $48,95 \mathrm{a}$ & $2,1583 \mathrm{a}$ & $1,7698 \mathrm{a}$ \\
120 & $57,62 \mathrm{a}$ & $49,31 \mathrm{a}$ & $2,1742 \mathrm{a}$ & $1,7828 \mathrm{a}$ \\
\hline Forma de aplicação* & & & & $1,7753 \mathrm{a}$ \\
\hline $100 \%$ plantio & $57,44 \mathrm{a}$ & $49,10 \mathrm{a}$ & $2,1650 \mathrm{a}$ & $1,7756 \mathrm{a}$ \\
\hline $50 \%$ plan. $+50 \%$ cob. & $55,83 \mathrm{a}$ & $49,11 \mathrm{a}$ & $2,1654 \mathrm{a}$ & \\
\hline
\end{tabular}

DIVMS = digestibilidade in vitro da matéria seca, \%; NDT = nutrientes digestíveis totais, \%; ED = energia digestível, Mcal $\mathrm{kg}^{-1} \mathrm{de} \mathrm{MS} ; \mathrm{EM}=$ energia metabolizável, Mcal kg ${ }^{-1}$ de MS, "Médias seguidas de mesma letra na coluna não diferem entre si pelo teste $\mathrm{F}$ a $5 \%$

e balanço nitrogenado negativo (COSTA et al., 2006), observa-se que as silagens produzidas neste estudo não atenderiam satisfatoriamente aos requerimentos protéicos mínimos dos ruminantes. Vilela et al. (2008) reportaram valores de PB de 8,5 e $8,1 \%$, para silagens confeccionadas a partir de plantas colhidas nos estádios $1 / 2$ e $2 / 3$ da linha de leite, respectivamente.

Observa-se na Tabela 4 que não ocorreu diferença nos valores de FDN do milho submetido a diferentes doses e formas de aplicação do potássio $(p>0,05)$, notandose valores de 49,$71 ; 50,10 ; 50,06$ e $49,63 \%$ para os tratamentos que receberam 0; 60; 90 e $120 \mathrm{~kg} \mathrm{ha}^{-1} \mathrm{de} \mathrm{K}_{2} \mathrm{O}$, respectivamente. Van Soest (1994) afirma que o teor de FDN é o fator mais limitante no consumo de volumosos, sendo que valores de FDN superiores a 55\% na MS correlacionam-se de forma negativa com o consumo de forragens e silagens. Os teores de FDN encontrados nesta pesquisa foram semelhantes aos relatados por Vilela $e t$ al. (2008), que encontraram valores de FDN de 49,1 e $53,9 \%$ para silagens confeccionadas a partir de plantas colhidas quando apresentavam 1/2 e 2/3 da linha de leite, respectivamente.

Os valores de FDA ficaram entre 39,45 e 39,91\% (Tabela 4), não ocorrendo variação significativa pelas doses e formas de aplicação de $K(p>0,05)$ utilizados. Este resultado pode estar relacionado com altas perdas de efluentes na silagem, embora esta medição não tenha sido realizada nesta pesquisa. Segundo Van Soest (1994), a fração fibrosa do material ensilado pode ser acrescida percentualmente em condições de intensa formação de efluente, uma vez que os componentes solúveis em água reduzem proporcionalmente ao aumento nos constituintes da parede celular.
Não houve efeito da adubação potássica sobre os teores de hemicelulose ( $p>0,05)$, o que pode ser atribuído à falta de variação nos valores de FDN e FDA (Tabela 4).

Os coeficientes de DIVMS não foram alterados pelas doses e formas de aplicação do potássio $(p>0,05)$ e os resultados variaram de 54,95 a 57,62\% (Tabela 5) quando as plantas utilizadas na confecção das silagens receberam 60 e $120 \mathrm{~kg} \mathrm{ha}^{-1}$ de $\mathrm{K}_{2} \mathrm{O}$, respectivamente. Segundo Vilela et al. (2008), a DIVMS tem alta correlação com os valores de FDA, o que explica os resultados obtidos nesta pesquisa, que são próximos aos valores observados pelos mesmos autores, 65,1 e 54,5\% para as silagens de plantas colhidas com $1 / 2$ e $2 / 3$ da linha de leite, respectivamente.

Não houve efeito das doses e formas de aplicação do $\mathrm{K}(\mathrm{p}>0,05)$ sobre os teores de NDT (Tabela 5), refletindo os teores de PB encontrados, pois há uma relação direta entre os mesmos (OLIVEIRA et al., 2010). Os teores de NDT encontrados foram de 49,22; 48,95; 48,95 e 49,31\%, com a utilização de 0; 60; 90 e $120 \mathrm{~kg} \mathrm{ha}^{-1}$ de $\mathrm{K}_{2} \mathrm{O}$, respectivamente. Neumann et al. (2004) avaliaram o desempenho de novilhos superprecoces trabalhando com silagens de milho utilizando $60 \mathrm{~kg} \mathrm{ha}^{-1}$ de $\mathrm{K}$ no plantio, e reportaram valores de NDT ao redor de $74 \%$.

Como pode ser verificado na Tabela 5 , não houve variação $(p>0,05)$ nos teores de ED e EM das silagens de milho em função das doses de $\mathrm{K}$, possivelmente por não ter ocorrido diferença na participação de grãos (Tabela 3). Também não houve diferença nos valores de ED e EM $(p>0,05)$ das silagens em função da época de aplicação do $\mathrm{K}$, mesmo ocorrendo maior participação de grãos nas plantas que receberam $100 \%$ do K no plantio (Tabela 3), sugerindo um efeito de diluição nesta variável. Pedro Velho et al. (2006) ressaltam que a silagem de milho fornece de 50 a $100 \%$ mais $\mathrm{ED}$ por hectare que qualquer outra forrageira. 
Os teores de ED e EM encontrados nesta pesquisa ficaram próximos aos descritos por Neumann et al. (2004), que avaliaram o desempenho de novilhos superprecoces alimentados com silagens de milho confeccionadas a partir de plantas que receberam $60 \mathrm{~kg} \mathrm{ha}^{-1}$ de $\mathrm{K}$ no plantio, e verificaram valores de ED e EM de 2,76 e 2,26 $\mathrm{Mcal} \mathrm{kg}^{-1}$ de MS, respectivamente.

\section{CONCLUSÕES}

1.Elevadas doses de potássio não proporcionaram mudanças para matéria seca, porcentagem de plantas acamadas, produtividade de matéria seca, produtividade de grãos e porcentagem de grãos na planta;

2.O emprego de todo o potássio no plantio proporciona maiores produtividades;

3. As diferentes doses e formas de aplicação de potássio não alteram as características químico-bromatológicas da silagem de milho.

\section{REFERÊNCIAS}

ANDREOTTI, M. et al. Crescimento do milho em função da saturação por bases e da adubação potássica. Scientia Agrícola, v. 58, n. 1 , p. $145-150,2001$.

CASTOLDI, G. et al. Sistemas de cultivo e uso de diferentes adubos na produção de silagem e grãos de milho. Acta Scientiarum Agronomy, v. 33, n. 1, p. 139-146, 2011.

COELHO, A. M.; FRANÇA, G. E. Nutrição e adubação de milho. Disponível em: <http://www.cnpms.embrapa.br/milho/ deficiencia/deficiencia.html>. Acesso em: 4 maio 2006.

COSTA, K. A. P. et al. Efeitos quantitativo e qualitativo do nitrogênio e do potássio no desenvolvimento da Brachiaria brizantha cv. MG-5. Revista Eletrônica Faculdade Montes Belos, v. 1, n. 1, p. 56-70, 2006.

CRUZ, P. J. et al. Influência do acamamento sobre o rendimento de grãos e outros caracteres em trigo. Revista Brasileira de Agrociência, v. 9, n. 1, p. 5-8, 2003.

FARIA, A. F. et al. Capacidade de suprimento de potássio em solos de Minas Gerais-Brasil. Spanish Journal of Soil Science, v. 2, n. 1, p. 26-37, 2012.

FERREIRA, D. F. SISVAR: um programa para análises e ensino de estatística. Revista Científica Symposium, v. 6, n. 2, p. 36-41, 2008.

GONÇALVES JUNIOR, A. C. et al. Produtividade do milho em resposta a adubação com NPK e Zn em Argissolo vermelhoamarelo eutrófico e Latossolo vermelho eutroférrico. Ciência \& Agrotecnologia, v. 31, n. 4, p. 1231-1236, 2007.
JOBIM, C. C. et al. Avanços metodológicos na avaliação da qualidade da forragem conservada. Revista Brasileira de Zootecnia, v. 36, p. 101-119, 2007. (Suplemento especial)

KARLEN, D. L. et al. Aerial accumulation and partitioning of nutrients by corn. Agronomy Journal, v. 80, n. 2, p. 232242,1988 .

MACITELLI, F. et al. Desempenho e rendimento de carcaça de bovinos mestiços alimentados com diferentes volumosos e fontes protéicas. Revista Brasileira de Zootecnia, v. 36, n. 6, p. 1917-1926, 2007.

MALAVOLTA, E. et al. Avaliação do estado nutricional das plantas: princípios e aplicações. 2. ed. Piracicaba: POTAFOS, 1997. 319 p.

MARSCHNER, H. Mineral nutrition of higher plants. 2. ed. London: Academic Press, 1995. 889 p.

MELLO, R. et al. Potencial produtivo e qualitativo de híbridos de milho, sorgo e girassol para ensilagem. Revista Brasileira de Agrociência, v. 10, n. 1, p. 87-95, 2004.

NEUMANN, M. et al. Avaliação de silagens de Sorgo (Sorghum bicolor, L. Moench) ou Milho (Zea mays, L.) na produção do novilho superprecoce. Revista Brasileira de Milho e Sorgo, v. 3, n. 3, p. 438-452, 2004.

OLIVEIRA, L. B. et al. Produtividade, composição química e características agronômicas de diferentes forrageiras. Revista Brasileira de Zootecnia, v. 39, n. 12, p. 2604-2610, 2010.

OTTO, R.; VITTI, G. C.; LUZ, P. H. C. Manejo da adubação potássica na cultura da cana-de-açúcar. Revista Brasileira de Ciência do Solo, v. 34, n. 4, p. 1137-1145, 2010.

PEDRO VELHO, J. et al. Alterações bromatológicas nas silagens de milho submetidas a crescentes tempos de exposição ao ar após "desensilagem". Ciência Rural, v. 36, n. 3, p. 916-923, 2006.

PEREIRA, M. N. et al. Ruminal degradability of hard or soft texture corn grain at three maturity stages. Scientia Agrícola, v. 61, n. 4 , p. $358-363,2004$.

PERRY, T. W. et al. Effect of potassium fertilization on chemical characteristics, yield and nutritive value of corn silage. Journal of Animal Science, v. 34, n. 4, p. 642-646, 1972.

POSSENTI, R. A. et al. Parâmetros bromatológicos e fermentativos das silagens de milho e girassol. Ciência Rural, v. 35, n. 5, p. 1185-1189, 2005.

RIBEIRO, A. C.; GUIMARÃES. P. T. C.; VENEGAS, V. H. A. (Ed.). Recomendações para uso de corretivos e fertilizantes em Minas Gerais - $5^{a}$ Aproximação. Viçosa, MG: $1999.359 \mathrm{p}$.

RODRIGUES, R. C. Avaliação químico-bromatológica de alimentos produzidos em terras baixas para nutrição animal. Pelotas: Empresa Brasileira de Pesquisa Agropecuária - EMBRAPA, 2009. 31 p.

SILVA, D. J.; QUEIROZ, A. C. Análise de alimentos: métodos químicos e biológicos. 3. ed. Viçosa, MG: UFV, 2002. 235 p. 
SILVA, T. C. et al. Populações microbianas, perfil fermentativo e composição de silagens de capim-elefante com jaca. Archivos de Zootecnia, v. 60, n. 230, p. 247-255, 2011.

TILLEY, J. M. A.; TERRY, R. A. A two-stage technique for the in vitro digestion of forage crops. Journal British of Grassland Society, v. 18, n. 2, p. 104-111, 1963.

VAN SOEST, P. J. et al. Symposium: carbohydrate methodology, metabolism and nutritional implications in dairy cattle. Journal of Dairy Science, v. 74, n. 10, p. 3583-3597, 1991.
VAN SOEST, P. J. Nutritional ecology of the ruminant. 2. ed. New York: Cornell University Press, 1994. 476 p.

VILELA, H. H. et al. Valor nutritivo de silagens de milho colhido em diversos estádios de maturação. Revista Brasileira de Zootecnia, v. 37, n. 7, p. 1192-1199, 2008.

ZOPOLLATTO, M. et al. Relações biométricas entre o estádio de maturação e a produtividade de híbridos de milho para produção de silagem. Revista Brasileira de Zootecnia, v. 38, n. 2 , p. $256-264,2009$. 